\title{
Ocorrência de oocistos de Cryptosporidium spp e cistos de Giardia sp e sua associação com Escherichia coli, Enterococcus spp indicadores bacteriológicos e turbidez em um reservatório tropical
}

Occurrence of Cryptosporidium spp oocysts and Giardia sp cysts and their association with Escherichia coli , Enterococcus spp and turbidity in a tropical reservoir

Ana Maria Moreira Batista Lopes (1)

Bióloga pelo Unicentro Metodista Izabela Hendrix. Mestre em Saneamento, Meio Ambiente e Recursos Hídricos pela Escola de Engenharia da Universidade Federal de Minas Gerais. Doutoranda em Ecologia, Conservação e Manejo da Vida Silvestre pelo Instituto de Ciências Biológicas da Universidade Federal de Minas Gerais.

Daniel Adolpho Cerqueira (3)

Biólogo pela Pontifícia Universidade Católica de Minas Gerais. Mestre em Microbiologia pelo Instituto de Ciências Biológicas da Universidade Federal de Minas Gerais. Doutor em Saneamento, Meio Ambiente e Recursos Hídricos pela Escola de Engenharia da Universidade Federal de Minas Gerais. Analista de Saneamento da Companhia de Saneamento de Minas Gerais.

Fabiana de Cerqueira Martins (4)

Bióloga pelo Instituto de Ciências Biológicas da Universidade Federal de Minas Gerais. Mestranda em Saneamento, Meio Ambiente e Recursos Hídricos pela Escola de Engenharia da Universidade Federal de Minas Gerais.

Valter Lúcio de Pádua (2)

Engenheiro civil pela Escola de Engenharia da Universidade Federal de Minas Gerais. Mestre e Doutor em Hidráulica e Saneamento pela Escola de Engenharia de São Carlos. Professor adjunto do Departamento de Engenharia Sanitária e Ambiental da Escola de Engenharia da Universidade Federal de Minas Gerais.

Endereço(1): Rua Canelinha, 174 - Coqueiros - Belo Horizonte - MG - CEP: 30880-360 - Brasil - Tel: (31) 8658-6455 - e-mail: ana_mb7@yahoo.com.br
Data de Entrada:

18-05-2010

Data de Aprovação: 09-08-2010

\section{RESUMO}

O presente estudo foi realizado no reservatório de Vargem das Flores, um manancial de abastecimento de água localizado na Região Metropolitana de Belo Horizonte, Minas Gerais, Brasil. O principal objetivo do trabalho foi caracterizar a ocorrência de oocistos de Cryptosporidium spp. e cistos de Giardia spp. e avaliar sua possível associação com a presença das bactérias Escherichia coli e Enterococcus spp. e com a turbidez da água. O programa de monitoramento do manancial teve a duração de um ano, com coletas mensais em quatro pontos e quatro profundidades. Os resultados das análises estatísticas indicaram fracas correlações entre os protozoários, as bactérias e a turbidez, assim como indicaram concentrações de (oo)cistos dos protozoários relativamente baixas. Porém a ocorrência desses protozoários foi ubíqua, oferecendo perigo à saúde humana, caso a água seja consumida sem tratamento prévio, como nas atividades de recreação.

\begin{abstract}
This study was done at the dam of Vargem das Flores, a reservoir supplying the cities of Belo Horizonte Metropolitan Region, Minas Gerais, Brazil. The major objective was to characterize the occurrence of Cryptosporidium spp. oocysts and Giardia spp. cysts evaluating their association with the presence of both bacteria Escherichia coli and Enterococcus spp. And turbidity in the Vargem das Flores reservoir. The monitoring program was carried out monthly for one year, sampling four sites at four depths. The stastical analyses results indicated poor correlation among protozoan, bacteria and turbidity. In the same way it was indicated low concentrations of Cryptosporidium spp. and Giardia spp. However the occurrence of the protozoan was ubiquitous, offering danger to human health if the water is consumed without previous treatment, like in recreational activities.
\end{abstract}

PALAVRAS-CHAVE: Cryptosporidium spp.; Giardia spp.; Escherichia coli; Enterococcus spp.; turbidez; usos da água; reservatório tropical

KEYWORDS: Cryptosporidium spp. and Giardia spp. (oo) cysts; Escherichia coli ; Enterococcus spp.; turbidity; water use; tropical reservoir

\section{INTRODUÇÃO}

Os protozoários Cryptosporidium e Giardia são os causadores, respectivamente, da criptosporidiose e da giardiose, doenças grastrointestinais cujo principal sintoma é a diarréia. A contaminação se dá através da ingestão das formas infecciosas dos protozoários, isto é, dos oocistos no caso do Cryptosporidium, e dos cistos de Giardia, que podem ser ingeridos pelo hospedeiro através do contato direto com as fezes, rota oral-fecal, ou ainda, pelo consumo de água e alimentos contaminados.

A água é cada vez mais apontada como veículo da criptosporidiose e da giardiose. Dentre os principais problemas para se controlar as infecções estão a contaminação frequente dos corpos d'água por esgotos domésticos, a ineficiência do monitoramento da água e o fato de muitos animais, domésticos e selvagens, serem reservatórios potenciais de Cryptosporidium e Giardia e contribuírem para ocorrência dos mesmos em mananciais utilizados para abastecimento público.

Segundo Karanis et al. (2007) pelo menos 325 surtos de transmissão hídrica documentados em todo o mundo são atribuídos a protozoários patogênicos. Entre esses surtos o 
Cryptosporidium parvum e a Giardia duodenalis contabilizaram, juntos, a maioria dos eventos epidêmicos. Tais dados abordaram desde o primeiro surto registrado em 1983 para Cryptosporidium em Cobham, Reino Unido, e o primeiro surto documentado para Giardia ocorrido no ano de 1954 em Portland, Oregon, EUA, até o ano de 2007, no qual a revisão foi publicada.

Os métodos normalmente utilizados para detecção desses protozoários são de custo superior àqueles utilizados ou aplicados à determinação dos indicadores bacterianos, fazendo-se necessário o estudo da utilização de organismos que possam servir de parâmetro na previsibilidade da ocorrência e remoção de oocistos de Cryptosporidium e cistos de Giardia. Em vista disso, para se garantir a segurança microbiológica das águas para consumo humano, é necessário o emprego de organismos que apresentem correlação com a ocorrência desses protozoários para que possam ser utilizados como possível parâmetro substituto.

Portanto, além do papel que exercem como indicadores de contaminação fecal, foi avaliada a existência de associação entre as bactérias Escherichia coli e Enterococcus spp., e os protozoários Cryptosporidium spp. e Giardia spp.

Além disso, faz-se necessário o uso de um padrão de referência consistente, tal como proposto na regulamentação Long Term 2 Enhanced Surface Water Treatment Rule LT2ESWTR (EPA, 2006). Essa regulamentação propõe níveis de remoção e/ou inativação mínimas necessárias para a redução da concentração de oocistos observada na água da fonte de forma que não determine um risco superior ao adotado como aceitável.

Em vista disso, esse trabalho teve como principais objetivos; (1) avaliar a ocorrência de oocistos de Cryptosporidium spp. e cistos de Giardia spp. no reservatório de Vargem das Flores; (2) verificar a existência de correlação entre a presença dos protozoários Cryptosporidium spp. e Giardia spp., e dos indicadores bacteriológicos E. coli e Enterococcus spp. e a turbidez; e ainda (3) categorizar as estações de monitoramento do manancial de acordo com as recomendações da Agência de Proteção Ambiental dos Estados Unidos (EPA), para a média das concentrações de oocistos de Cryptosporidium spp.

\section{METODOLOGIA}

\subsection{Descrição do local de estudo}

O presente estudo foi realizado na represa de Vargem das Flores, a qual foi inaugurada em 1972 e está situada nas coordenadas geográficas 19 53’44,99 S e 44 09'01,56” W coordenadas referentes à captação da Estação de Tratamento de Água (GOMES, 2008).

A represa (Figura 1) está localizada na parte sudoeste da Região Metropolitana de Belo Horizonte (RMBH), dentro da bacia de drenagem do Rio Paraopeba, e abastece sete cidades da $\mathrm{RMBH}$, inclusive a própria capital.
Atualmente, a represa possui um espelho d'água de 5,2 quilômetros quadrados, com um volume de 44 milhões de metros

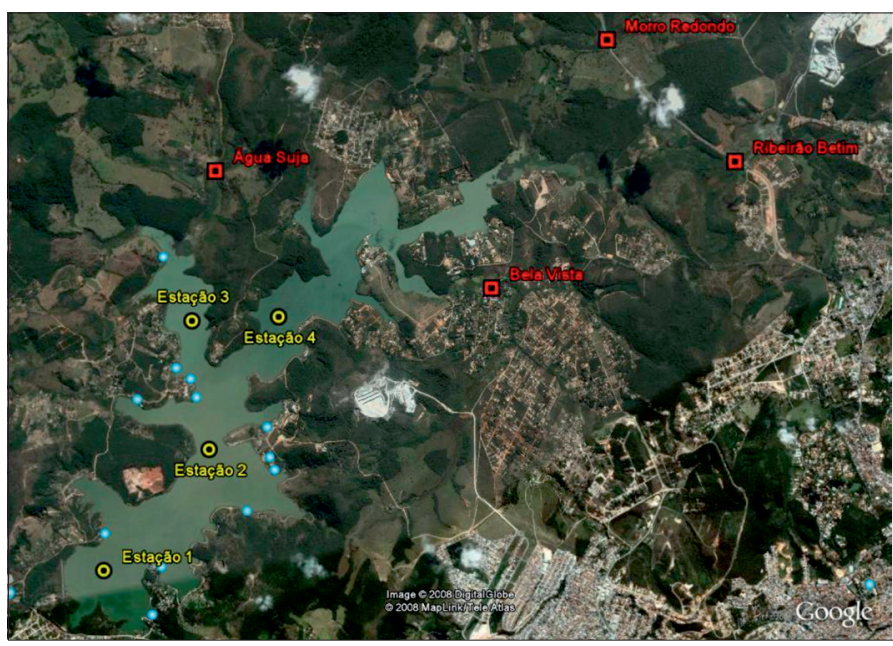

Figura 1: Imagem satélite do manancial Vargem das Flores com a localização das estações e córregos de coleta da presente pesquisa. Modificado de Google Earth (2008).

cúbicos. A água acumulada tem a sua origem nos principais tributários: Córrego Água Suja, Ribeirão Betim, Córrego Morro Redondo, Córrego Bela Vista e Córrego Batatal, sendo que, com exceção deste último, todos os outros recebem contribuição de esgotos. A represa possui profundidade máxima de 18 metros, e uma profundidade média de 6 metros. A tecnologia de tratamento de água é a filtração direta descendente, com uma vazão média de 1,0 metro cúbico por segundo, para atender a uma população de aproximadamente 400.000 habitantes (SOUZA, 2003).

O fluxograma das principais atividades realizadas neste trabalho está representado na Figura 2.
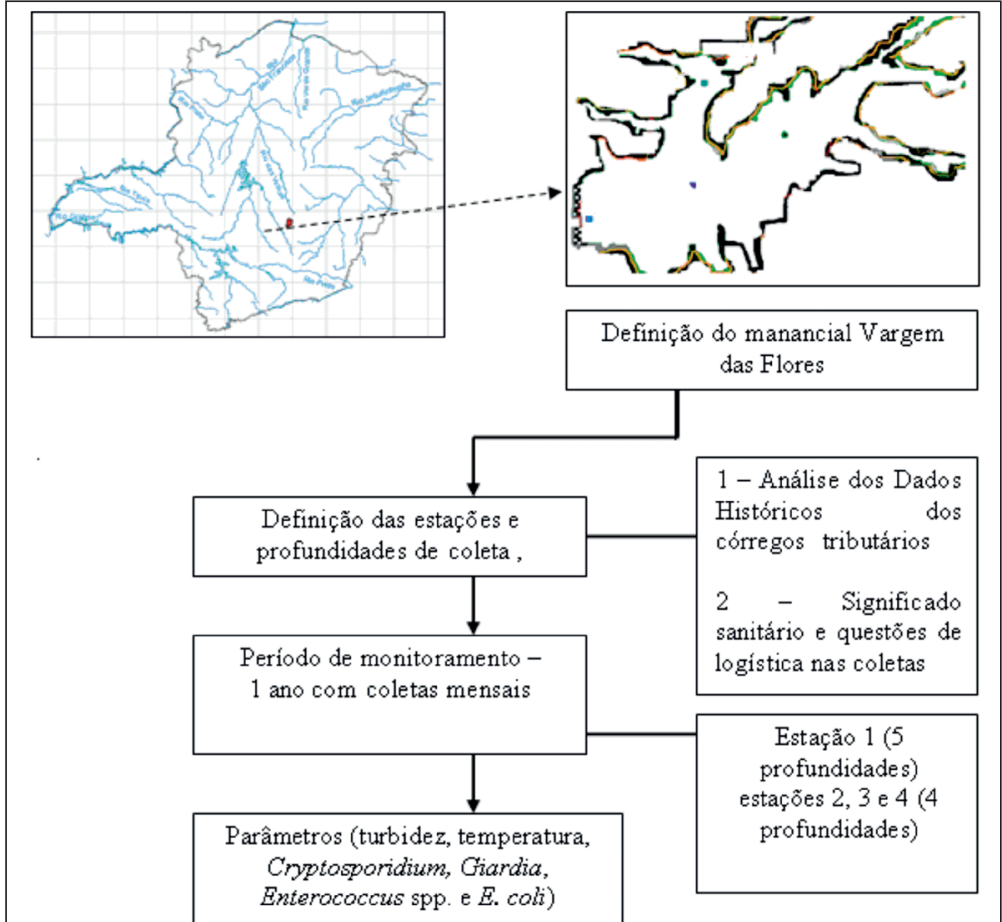

Obs.: As análises de Cryptosporidium e Giardia foram realizadas apenas na profundidade de extinção de disco de Secchi.

Figura 2: Fluxograma de atividades da pesquisa 


\subsection{Identificação das estações para coleta de amostras}

Foram definidas quatro estações para a realização das coletas: estação 1 - coleta realizada em cinco profundidades (Superfície, Secchi, 5m, 10m e fundo) e estações 2, 3 e 4, com coletas realizadas em quatro profundidades (Superfície, Secchi, $5 \mathrm{~m}$ e fundo). O motivo da existência de um ponto de coleta a mais na estação 1 é o fato da mesma possuir valores de profundidade máxima superiores em relação as demais estações. É importante ressaltar que essas estações foram selecionadas devido ao seu significado sanitário, pois são caracterizadas por uma densa ocupação e pela prática de atividades recreacionais, além disso, a escolha também se baseou em questões de logística nas coletas e no fato de haver registros históricos de monitoramento da água nestes pontos por parte da Companhia de Saneamento.

A caracterização da área de estudo foi feita com o somente na profundidade de extinção do disco de Secchi devido ao significado limnológico desta profundidade. Ademais, o elevado custo das análises inviabilizaria a pesquisa economicamente, caso fossem analisadas amostras de todas as profundidades superfície, Secchi, 5m, 10m (no caso da estação 1) e fundo.

\subsubsection{Escherichia coli, Enterococcus spp e turbidez}

As técnicas de coleta, preservação e transporte das amostras para as análises bacteriológicas (Escherichia coli, Enterococcus spp.) e para a quantificação da turbidez foram baseadas no Standard Methods for the Examination of Water and Wasterwater (APHA, 2005). A Tabela 2 apresenta todos os locais, parâmetros, frequências e referência dos métodos utilizados no monitoramento da represa de Vargem das Flores. auxílio de um barco motorizado (Tohatsu - 18). À medida que as estações de coleta eram percorridas os pontos foram delimitados por um Sistema de Posicionamento Global (GPS), da marca Garmin, modelo eTrex Legend.

Após isso, as coordenadas foram lançadas e marcadas na própria fotografia (satélite) do manancial, através do site Google Earth (2008), conforme mostrado na Figura 1. A Tabela 1 apresenta a descrição das estações de coleta.
Tabela 2: Localização, parâmetros, frequência e métodos utilizados para o monitoramento da represa de Vargem das Flores, MG, no período de dezembro de 2007 a novembro de 2008.

\begin{tabular}{|c|l|l|l|l|}
\hline Local & Pontos & Parâmetro & Frequência & \multicolumn{1}{c|}{ Método e Referência } \\
\hline & $\begin{array}{l}\text { Superfície, Secchi, } \\
5 \mathrm{~m}, 10 \mathrm{~m} \text {, Fundo }\end{array}$ & Turbidez & mensal & $\begin{array}{l}\text { Nefelométrico em Turbidímetro digital da } \\
\text { marca Hach, modelo 2100N (APHA, 2005 } \\
-2130 \text { B). }\end{array}$ \\
\cline { 2 - 5 } & $\begin{array}{l}\text { Superfície, Secchi, } \\
5 \mathrm{~m}, 10 \mathrm{~m}^{*}, \text { Fundo }\end{array}$ & Temperatura & mensal & $\begin{array}{l}\text { Termômetro }{ }^{\circ} \mathrm{C} \text { (Hg) (APHA, 2005 - 2550 } \\
\text { B). }\end{array}$ \\
\cline { 2 - 5 } $\begin{array}{l}\text { Estações } \\
(1 \text { a 4) }\end{array}$ & $\begin{array}{l}\text { Superfície, Secchi, } \\
5 \mathrm{~m}, 10 \mathrm{~m}^{*}, \text { Fundo }\end{array}$ & E. coli & mensal & $\begin{array}{l}\text { Teste substrato enzimático (APHA, 2005 - } \\
9223 \text { B). }\end{array}$ \\
\cline { 2 - 5 } & $\begin{array}{l}\text { Superfície, Secchi, } \\
5 \mathrm{~m}, 10 \mathrm{~m}^{*}, \text { Fundo }\end{array}$ & Enterococcus spp. & mensal & $\begin{array}{l}\text { Técnica substrato definido (ASTM, 2005 - } \\
\text { D6503-99). }\end{array}$ \\
\cline { 2 - 5 } & Secchi & Cryptosporidium spp. & mensal & Método 1623 (EPA, 2005) \\
\cline { 2 - 5 } & Secchi & Giardia spp. & mensal & Método 1623 (EPA, 2005) \\
\hline
\end{tabular}

* profundidade coletada apenas na estação 1.

Tabela 1: Descrição e coordenadas dos locais de coleta.

\begin{tabular}{|c|l|c|}
\hline Local & \multicolumn{1}{|c|}{ Descrição } & Coordenadas dos pontos \\
\hline Estação 1 & $\begin{array}{l}\text { Estação mais profunda, localizada junto à torre de } \\
\text { tomada d'água da ETA }\end{array}$ & $19^{\circ} 55.056^{\prime} \mathrm{S}$ e $44^{\circ} 09.933^{\prime} \mathrm{W}$ \\
\hline Estação 2 & Encontro dos dois braços principais da represa & $19^{\circ} 54.398^{\prime} \mathrm{S}$ e $44^{\circ} 09.322^{\prime} \mathrm{W}$ \\
\hline Estação 3 & Ponto de afluência do córrego Água Suja & $19^{\circ} 53.701^{\prime} \mathrm{S}$ e $44^{\circ} 09.421^{\prime} \mathrm{W}$ \\
\hline Estação 4 & Ponto de afluência do ribeirão Betim & $19^{\circ} 53.679^{\prime} \mathrm{S}$ e $44^{\circ} 08.892^{\prime} \mathrm{W}$ \\
\hline
\end{tabular}

Em campo, durante a coleta das amostras, foram registradas a data, horário, condições do tempo, temperatura do ambiente e das amostras. As amostras foram mantidas sob refrigeração a $<10 \mathrm{C}$ até o momento das análises.

\subsection{Procedimentos de coleta e métodos de análise}

\subsubsection{Cryptosporidium spp e Giardia spp}

Para a realização das coletas para análise dos (oo) cistos dos protozoários Cryptosporidium spp. e Giardia spp. os galões plásticos com capacidade para $10 \mathrm{~L}$ foram previamente lavados com Extran diluído e esterilizados por calor úmido (121 C, 1,5 atmosfera, 15 minutos) em autoclave. Em seguida, foram ambientados com $50 \mathrm{~mL}$ de solução tampão fosfato com Tween 20, $1 \%$ concentrada, por agitação manual por três vezes. A secagem dos galões ocorreu à temperatura ambiente com prévia vedação do gargalo.

A coleta da água na represa foi feita com auxílio da garrafa coletora de Van Dorn, sempre na profundidade de extinção do disco de Secchi, utilizada para avaliar a extensão da zona eufótica. O monitoramento para os protozoários foi realizado
2.3.3 Determinações de (oo)cistos de Cryptosporidium spp. e Giardia spp. nas amostras de água

A identificação e quantificação de (oo)cistos de Cryptosporidium spp. e Giardia spp. foram realizadas de acordo com o Método 1623 (EPA 2005). As etapas, materiais e reagentes utilizados na análise estão resumidos na Tabela 3. O método 1623 - Cryptosporidium e Giardia em água foi preconizado para a determinação desses protozoários em amostras de água bruta ou tratada. Ele compreende as etapas de Filtração, Concentração, Separação Imunomagnética (IMS) e Identificação Microscópica, como referido na Tabela 3. A confirmação é feita pelo corante DAPI (4', 6'-diamidino2-fenilindol) e pelo CID (microscopia de contraste de interferência diferencial). 
Tabela 3: Resumo do material para coleta e para os métodos de análise das amostras de água para pesquisa de (oo)cistos de Cryptosporidium spp. e Giardia spp. pelo método 1623 EPA 2005.

\begin{tabular}{|c|c|c|}
\hline Etapa & Material & Reagentes \\
\hline Coleta (APHA, 2005) & $\begin{array}{l}\text { Galões plásticos com capacidade para } 10 \mathrm{~L} \\
\text {; autoclave; recipientes de plástico c/ } \\
\text { capacidade para } 8 \mathrm{~L} \text {; garrafa coletora de } \\
\text { Van Dorn; disco de Secchi }\end{array}$ & $\begin{array}{l}\text { Solução de Tampão Fosfato c/ Tween } \\
20-1 \% \text { concentrada, } \mathrm{pH} 7,4 \text {; Extran } \\
\text { diluído (1). }\end{array}$ \\
\hline Filtração (1623 EPA 2005) & $\begin{array}{llll}\text { Módulos de } & \text { filtro em } & \text { espuma de } \\
\text { porosidade } 1 \mu \mathrm{m} & \text { (Sistema } & \text { Filta-Max - } \\
\text { IDEXX/EUA); } & \text { bomba } & \text { peristáltica } \\
\text { (Modelo: R60 } & \text { DZ71D4 } & \text { /Fabricante: } \\
\text { Sew/Brasil) } & & \\
\end{array}$ & $(1)$ \\
\hline Eluição (1623 EPA 2005) & $\begin{array}{l}\text { Stomacher (Modelo: MK1204/ Fabricante: } \\
\text { Boitton/Brasil) }\end{array}$ & $(1)$ \\
\hline $\begin{array}{l}\text { Concentração (1623 EPA } \\
\text { 2005) }\end{array}$ & $\begin{array}{l}\text { Béquer; tubos de centrífuga de } 250 \text { e } 50 \\
\text { mL; balança digital; centrífuga (Modelo: } \\
\text { CT 6000D/ Fabricante: Cientec/Brasil) } \\
\text { com aceleração de } 1500 \mathrm{~g} \text {, correspondente } \\
\text { neste modelo a } 2700 \mathrm{rpm}-\text { por } 15 \\
\text { minutos; vórtex (Modelo: MS1 Minishaker } \\
\text { / Fabricante IKA) }\end{array}$ & (1) \\
\hline $\begin{array}{l}\text { Purificação - Separação } \\
\text { Imunomagnética - Sistema } \\
\text { Dynal/Biobeads (1623 EPA } \\
\text { 2005) }\end{array}$ & $\begin{array}{l}\text { Tubo de lado chato (Leigthon); kit Dynal } \\
\text { (Oslo/Noruega); agitador rotativo } \\
\text { (Homogeneizador sanguíneo - Modelo: } \\
\text { AP22 /Fabricante: Phoenix), a } 18 \text { rpm por } \\
1 \text { hora; concentrador magnético MPC-1 - } \\
\text { Magnetic Particle Concentrator; tubo } \\
\text { Eppendorf; banho seco (Fabricante: } \\
\text { Quimis) }\end{array}$ & $\begin{array}{l}\text { (1); água destilada; reagentes de } \\
\text { separação imunomagnética (Crypto- } \\
\text { Combo e Giardia-Combo); solução } \\
\text { tampão-A 10x concentrada e tampão- } \\
\text { B 10x concentrada (Kit Dynal) }\end{array}$ \\
\hline $\begin{array}{l}\text { Detecção e quantificação - } \\
\text { Imunofluorescência e } \\
\text { coloração com DAPI (1623 } \\
\text { EPA 2005) }\end{array}$ & $\begin{array}{l}\text { Kit Merifluor/EUA; } r \\
\text { DAPI/Sigma (4',6-diamidino-2-fenilindolorão } \\
\text { - Contraste de Interferência Diferencial } \\
\text { (CID) - (modelo do microscópio: DMLB/ } \\
\text { Fabricante: Leica/Alemanha); câmara } \\
\text { úmida*; pipeta de Pasteur; lamínula } \\
\text { Perfecta 24 x } 60 \mathrm{~mm}\end{array}$ & $\begin{array}{l}\text { Solução de Tampão Fosfato sem } \\
\text { Tween } 20-1 \% \text { concentrada, } \mathrm{pH} 7,4 \mathrm{e} \\
\text { Solução de Tampão Fosfato c/ Tween } \\
20-1 \% \text { concentrada, pH } 7,4 ; \text { meio } \\
\text { de montagem (glicerol); corante } \\
\text { DAPI/Sigma (4', 6-diamidino-2- } \\
\text { fenilindol) }\end{array}$ \\
\hline
\end{tabular}

* composto por um recipiente plástico forrado com filtros de papel levemente umedecidos com água destilada e incubado à temperatura ambiente no escuro.

2.4 Categorização das estações monitoradas segundo as recomendações da EPA (2006)

A EPA, ao elaborar a LT2 ESWTR, estabeleceu créditos em log-remoção de Cryptosporidium para cada etapa inserida ao longo do processo de abastecimento de água de consumo, desde a escolha do tipo de manancial até as alternativas tecnológicas mais eficientes de remoção e de inativação desses protozoários (CORNWELL et al., 2003). Além disso, a norma propõe tratamento adicional para Cryptosporidium, através do estabelecimento de categorias para os sistemas de abastecimento em função das concentrações médias de oocistos encontradas na água da fonte. Cada categoria direciona o sistema a um nível mínimo de remoção provido por uma técnica de tratamento e processos a serem adicionados em função da concentração média de oocistos na água da fonte (EPA, 2006). Essa categorização "Bins" é baseada em resultados de monitoramento da água da fonte. Para chegar a essa classificação, a EPA (2006) determina que cada sistema ( $>10.000$ habitantes) determine a concentração de Cryptosporidium calculando a média de resultados de amostras individuais de um ou mais anos de monitoramento. Aos sistemas de abastecimento classificados em "Bins" de concentrações mais baixas não são requereridos tratamentos adicionais, enquanto que os sistemas onde foram atribuídos "Bins" de concentrações mais altas devem adicionar processos que reduzam as concentrações de Cryptosporidium - Tabela 4. Ademais, é importante ressaltar que, o risco tolerável estabelecido na EPA é de $10^{-4}$ PPA (por pessoa ano). 
Tabela 4: Concentração média de oocistos de Cryptosporidium na água bruta e o tratamento adicional requerido para obtenção dos créditos.

\begin{tabular}{|l|c|l|}
\hline $\begin{array}{c}\text { Concentração média } \\
\text { de oocistos }\end{array}$ & Bins & \multicolumn{1}{|c|}{ Tratamento adicional requerido conforme a LT2ESWTR } \\
\hline$<0,075$ oocistos/L & 1 & $\begin{array}{l}\text { Não é necessário nenhum tratamento adicional além do ciclo completo, filtração } \\
\text { lenta e direta. }\end{array}$ \\
\hline $\begin{array}{l}>0,075 \text { até }<1,0 \\
\text { oocisto/L }\end{array}$ & 2 & $\begin{array}{l}\text { O sistema deve adicionar processo de tratamento que reduza, em pelo menos, 1 log } \\
\text { a concentração de Cryptosporidium. }\end{array}$ \\
\hline $\begin{array}{l}>1,0 \text { até }<3,0 \\
\text { oocisto/L }\end{array}$ & 3 & $\begin{array}{l}\text { O sistema deve adicionar processo de tratamento para remover, pelo menos, } 2 \text { log, } \\
\text { sendo } 1 \text { log a partir do uso de ozônio, } \mathrm{ClO}_{2}, \mathrm{UV}, \text { membranas, filtros de cartucho ou } \\
\text { filtração em margem. }\end{array}$ \\
\hline$? 3,0$ oocisto/L & 4 & $\begin{array}{l}\text { O sistema deve adicionar processo de tratamento para remover, pelo menos, } 2,5 \text { log, } \\
\text { sendo 1 log a partir do uso de ozônio, } \mathrm{ClO}_{2}, \mathrm{UV}, \text { membranas, filtros de cartucho ou } \\
\text { filtração em margem. }\end{array}$ \\
\hline
\end{tabular}

recuperação do método 1623 EPA (2005), para detecção de oocistos de Cryptosporidium e cistos de Giardia nas amostras de água bruta da represa de Vargem das Flores, foram obtidos resultados com grau de recuperação em torno de $40 \%$ para oocistos e $30 \%$ para cistos, utilizando-se kits EASYSEED com $100( \pm 1)$ oocistos por suspensão testada. Esses percentuais foram aplicados sobre os resultados finais de acordo com a Tabela 8, e condizem com os resultados de recuperação previa-

Logo, no presente trabalho também foi realizada a classificação das estações nas categorias - "Bins" - estabelecidas pela LT2 ESWTR - EPA (2006) feita a partir da média aritmética das concentrações de oocistos de Cryptosporidium spp. obtidas durante 12 meses, com análise de 12 amostras, em cada uma das estações separadamente.

\subsection{Controle da Qualidade da Análise - CQA}

Foi avaliado o percentual de recuperação do método 1623, EPA (2005), para as contagens de (oo)cistos com os kits EASYSEED

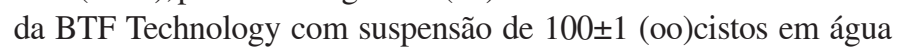
bruta da represa de Vargem das Flores. Portanto, para classificação das estações nas categorias - "Bins" os resultados foram corrigidos aplicando os resultados dos percentuais de recuperação.

\subsection{Análise Estatística dos Resultados}

Os dados referentes à ocorrência dos (oo)cistos dos protozoários Cryptosporidium spp. e Giardia spp. Foram comparados em todas as estações fazendo uso do teste Kruskal Wallis (teste não-paramétrico), com nível de significância de 5\%.

Os testes de Spearman foram utilizados para a avaliação da correlação entre os (oo)cistos de Cryptosporidium spp. e de Giardia spp. e os parâmetros (E. coli, Enterococcus spp. e turbidez), em cada estação de coleta da represa de Vargem da Flores na profundidade de extinção do disco de Secchi.

Ademais, é importante ressaltar que, a interpretação da estatística dos dados foi feita com cautela tendo em vista a limitação imposta pelo número relativamente pequeno de dados (12).

\section{RESULTADOS E DISCUSSÃO}

\subsection{Avaliação do percentual de recuperação do método}

Em relação ao grau mente relatados na literatura.

3.2 Avaliação das concentrações de cistos de Giardia spp. e de oocistos de Cryptosporidium spp. nas estações 1, 2, 3 e 4

A Tabela 5 apresenta as concentrações de cistos de Giardia spp. verificadas nas estações 1, 2, 3 e 4 durante o período de dezembro de 2007 a novembro de 2008.

Os resultados revelaram que as concentrações de cistos de Giardia spp. encontradas na represa de Vargem das Flores oscilaram entre 0 a 8 cistos em $10 \mathrm{~L}$ de amostra, com percentual de amostras positivas de $66,6 \%$ na estação 3 e de $50 \%$ nas estações 1,2 e 4 . Essas concentrações de cistos de Giardia spp. foram relativamente baixas, quando comparadas com as concentrações encontradas em mananciais lóticos, tais como os estudados por FRANCO et al., 2001; MACHADO \& CERQUEIRA, 2003. No entanto, foi similar ao resultado encontrado por Hachich et al. (2004), que ao estudarem diversos mananciais para abastecimento público do estado de São Paulo verificaram que, em geral, mananciais lênticos apresentavam menor ocorrência de Giardia spp. e Cryptosporidium spp. que os mananciais lóticos.

No Japão, Hashimoto et al. (2001) avaliaram a presença de cistos de Giardia em um sistema de abastecimento de água que operava com ciclo completo. Os resultados mostraram que os cistos de Giardia foram detectados em três, i. é, $12 \%$ das 26 amostras.

Essa menor ocorrência de protozoários em reservatórios
Tabela 5: Concentrações de cistos de Giardia spp. em todas as estações monitoradas com os respectivos percentuais de amostras positivas.

\begin{tabular}{|c|c|c|c|c|}
\hline \multirow[t]{2}{*}{ Mês } & \multicolumn{4}{|c|}{ Cistos de Giardia 10/L } \\
\hline & Estação 1 & Estação 2 & Estação 3 & Estação 4 \\
\hline Dez/07 & 4 & 4 & 4 & 2 \\
\hline Jan/08 & N.D. & N.D. & N.D. & N.D. \\
\hline $\mathrm{Fev} / 08$ & N.D. & N.D. & N.D. & N.D. \\
\hline Mar/08 & 2 & 1 & N.D. & N.D. \\
\hline $\mathrm{Abr} / 08$ & 1 & 1 & 1 & 3 \\
\hline Mai/08 & N.D. & N.D. & 1 & 2 \\
\hline Jun/08 & N.D. & N.D. & N.D. & 1 \\
\hline $\mathrm{Jul} / 08$ & N.D. & 1 & 3 & 1 \\
\hline Ago/08 & N.D. & 1 & 8 & 2 \\
\hline Set/08 & 1 & 1 & 2 & N.D. \\
\hline Out/08 & 2 & N.D. & 7 & N.D. \\
\hline Nov/08 & 1 & N.D. & 1 & N.D. \\
\hline$\% \operatorname{amostras}(+)$ & $50 \%$ & $50 \%$ & $66,6 \%$ & $50 \%$ \\
\hline
\end{tabular}

N.D.: Não Detectado (para fins de cálculo da média foi considerado valor zero); \% amostras +: percentual de amostras positivas p/ cistos de Giardia spp. em um total de 12 análises por estação. 
é, segundo Brookes et al. (2004), atribuída aos fatores de remoção, inclusive sedimentação e inativação por temperatura, radiação UV e predação. De acordo com os autores, o destino e transporte dos patógenos ao longo do reservatório estão intimamente relacionados aos processos hidrodinâmicos que ocorrem em ambientes lênticos, como por exemplo, o tempo de residência da água, e à carga de patógenos afluente à represa. Um bom exemplo da influência dos processos hidrodinâmicos na carga de patógenos foi mostrado em um estudo isolado de três reservatórios em Biesbosch, Países Baixos, no qual a estocagem com longos períodos de detenção (cerca de oito meses) apresentou reduções de 2,3 logs de Giardia, 1,4 a 1,9 logs de Cryptosporidium, 2,2 logs de E. coli e 1,7 logs de Enterococcus spp. (WHO, 2004), sendo que em condições naturais, a taxa de decaimento de oocistos em ambientes aquáticos é 0,005 a 0,037 unidades log por dia (WHO, 2006).

Além disso, a ressuspensão de agentes patogênicos dos sedimentos do fundo do corpo d'água também influencia na distribuição dos protozoários no reservatório.

Os resultados das análises de oocistos de Cryptosporidium spp. das amostras de água das estações 1, 2, 3 e 4 podem ser observados na Tabela 6.

As concentrações de oocistos de Cryptosporidium spp. variaram entre 0 a 4 oocistos/10 L durante o período de monitoramento (Tabela 5) com percentual de $50 \%$ de amostras positivas na estação 1 , seguido pela estação 4 com $41,6 \%$ de amostras positivas, estação 2 com 33,3\%, e estação $3 \operatorname{com} 8,3 \%$.

Essas ocorrências acompanham concentração verificada por Leal (2005), que encontrou variações de 1 a 3 oocistos Cryptosporidium/10 L na água bruta do rio Itapecerica em Divinópolis, MG, com percentual de 50\% de ocorrência. Entretanto, em pesquisa realizada em dois mananciais de abastecimento de água na cidade de Viçosa, MG, ambos lóticos, foram verificadas concentrações médias de oocistos de Cryptosporidium da ordem de 6 a 20 oocistos/L, ou 60 a 200 oocistos/10 L (HELLER et al., 2004).

No Japão, Hashimoto et al. (2001) também avaliaram a presença de (oo)cistos de Cryptosporidium e os resultados mostraram que os oocistos foram detectados em nove das 26 amostras analisadas, o que equivale a uma porcentagem de $35 \%$.

Ademais, é possível observar nas Tabelas 5 e 6 que houve maior concentração de cistos de Giardia spp. em todas as

Tabela 6: Concentrações de oocistos de Cryptosporidium spp. em todas as estações monitoradas com os respectivos percentuais de amostras positivas.

\begin{tabular}{|c|c|c|c|c|}
\hline \multirow[t]{2}{*}{ Mês } & \multicolumn{4}{|c|}{ Oocistos de Cryptosporidium/10 L } \\
\hline & Estação 1 & Estação 2 & Estação 3 & Estação 4 \\
\hline Dez/07 & 1 & N.D. & N.D. & 1 \\
\hline $\operatorname{Jan} / 08$ & 2 & 1 & 4 & 4 \\
\hline Fev/08 & N.D. & 4 & N.D. & 4 \\
\hline Mar/08 & 1 & 3 & N.D. & N.D. \\
\hline $\mathrm{Abr} / 08$ & 1 & 2 & N.D. & 1 \\
\hline Mai/08 & N.D. & N.D. & N.D. & N.D. \\
\hline Jun/08 & N.D. & N.D. & N.D. & N.D. \\
\hline Jul/08 & N.D. & N.D. & N.D. & 1 \\
\hline Ago/08 & N.D. & N.D. & N.D. & N.D. \\
\hline Set/08 & 1 & N.D. & N.D. & N.D. \\
\hline Out/08 & 1 & N.D. & N.D. & N.D. \\
\hline Nov/08 & N.D. & N.D. & N.D. & N.D. \\
\hline$\%$ amostras $(+)$ & $50 \%$ & $33,3 \%$ & $8,3 \%$ & $41,6 \%$ \\
\hline
\end{tabular}

N.D.: Não Detectado (para fins de cálculo da média foi considerado valor zero); \% amostras +: percentual de amostras positivas p/ oocistos de Cryptosporidium spp. em um total de 12 análises por estação.

estações monitoradas, quando comparada com a concentração de oocistos de Cryptosporidium spp. O mesmo fato foi observado por Lee et al. (2007) que examinaram a ocorrência de oocistos de Cryptosporidium e cistos de Giardia em um rio na Coréia, e perceberam que em geral, o número de cistos de Giardia foi maior do que o dos oocistos de Cryptosporidium, no entanto as diferenças foram tão mínimas que não puderam ser confirmadas estatisticamente.

Ademais, a baixa concentração tanto de cistos, quano de oocistos pode ser devido a predação de patógenos pelo zooplâncton e a subsequente incorporação de agentes patogênicos em pellets fecais também influencie na fixação desses a outras partículas do efluente. Por conseguinte, a agregação de (oo) cistos ao material particulado, ou a integração dos mesmos à matéria orgânica, irá influenciar na taxa de patógenos e favorecer o decaimento dos (oo)cistos na coluna d'água; pois, embora a sedimentação individual dos (oo)cistos seja extremamente lenta, a capacidade de se aderirem a partículas aumenta potencialmente sua velocidade de sedimentação. Sendo assim, a sedimentação provavelmente contribuiu para uma menor concentração de (oo) cistos na camada superficial (BROOKES et al., 2004).

A distribuição dos (oo)cistos de Cryptosporidium spp. e de Giardia spp. em todas as estações monitoradas está apresentada nas Figuras 3 e 4. 


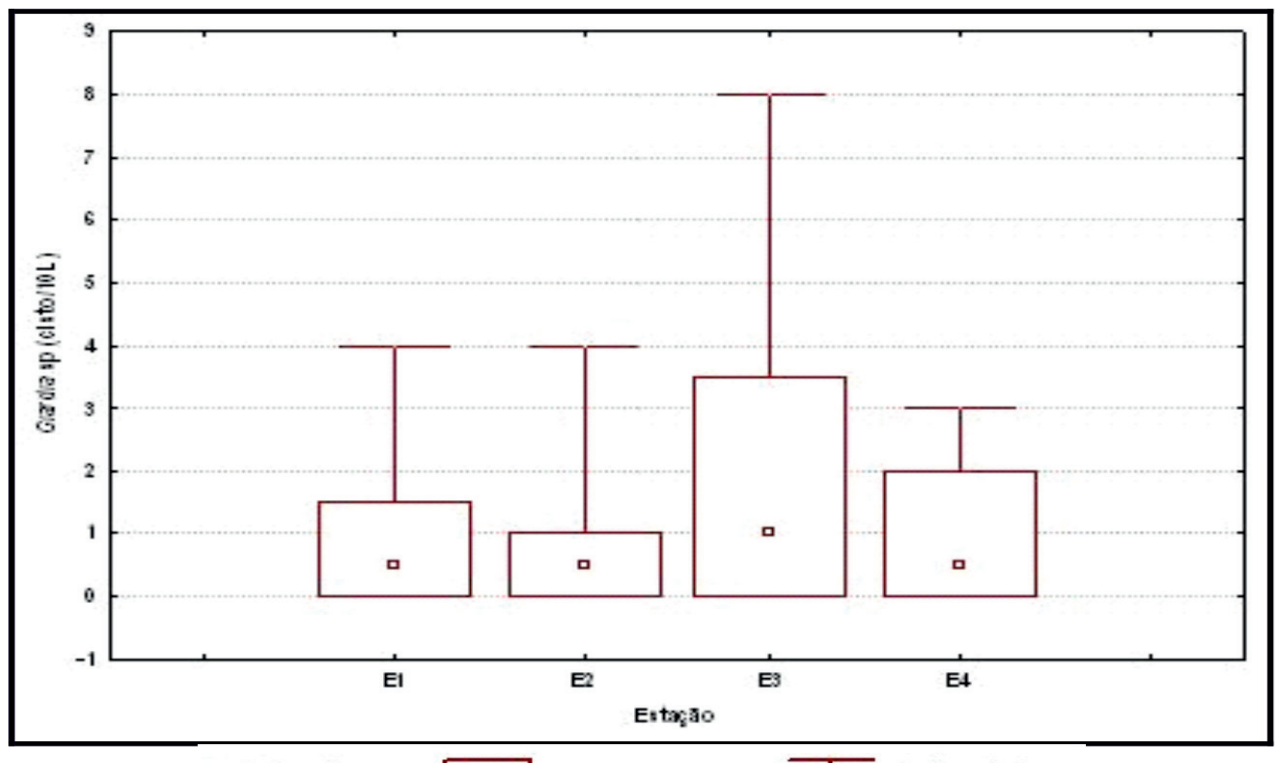

$\square$ Mediana $\square$ 25\%-75\% $\square$ Min-Max

Figura 3: Gráfico "box-whisker" das concentrações de cistos de Giardia (cistos/10 L) no período de dezembro de 2007 a novembro de 2008, estações 1, 2,3 e 4, Vargem das Flores - MG.

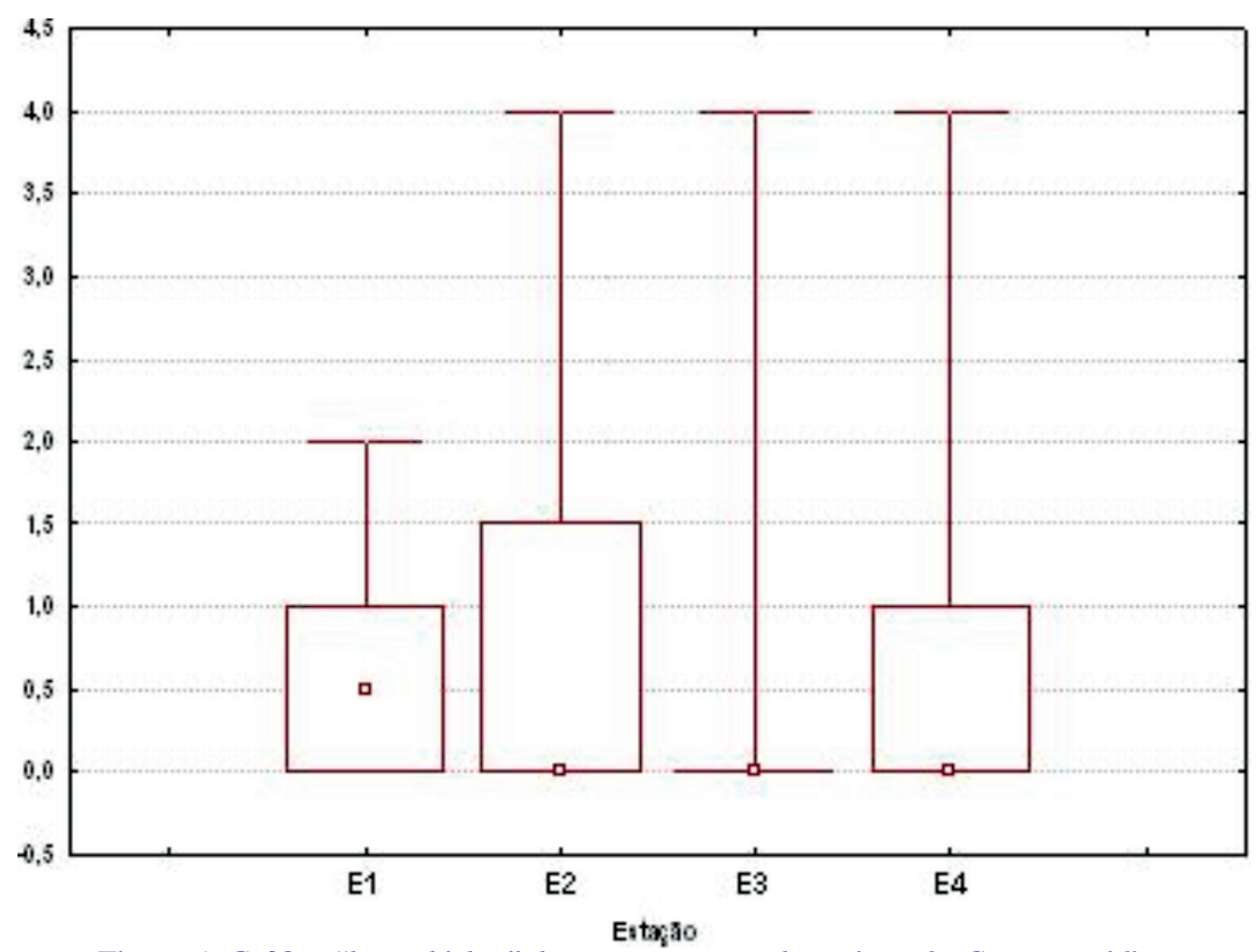

Figura 4: Gráfico "box-whisker" das concentrações de oocistos de Cryptosporidium (oocistos/10 L) no período de dezembro de 2007 a novembro de 2008, estações 1, 2,3 e 4,

Vargem das Flores - MG.

As concentrações de cistos de Giardia spp. não apresentaram diferenças estatisticamente significativas ao nível de significância de 95\%, entre as estações monitoradas, o que caracteriza uma distribuição aparentemente homogênea dos cistos de Giardia spp. ao longo da represa de Vargem das Flores e, portanto, nenhuma estação de monitoramento poderia ser considerada melhor ou pior tendo em vista este parâmetro.

Da mesma forma, o teste estatístico não revelou diferenças significativas das concentrações de oocistos de
Cryptosporidium spp. entre as estações.

Embora as concentrações dos (oo)cistos de Cryptosporidium spp. e Giardia spp. tenham sido relativamente baixas, conforme apresentado nas Tabelas 5 e 6, essa ocorrência parece ter sido ubíqua e homogênea ao longo de toda a extensão da represa de Vargem das Flores (Figuras 3 e 4), pois, mesmo na estação à jusante, distante do desaguamento dos córregos tributários, como é o caso da estação 1, os (oo)cistos estavam presentes. 


\section{artigos técnicos}

\subsection{Correlação entre protozoários, bactérias e turbidez} os protozoários Cryptosporidium spp. e Giardia spp. e os parâmetros E. coli, Enterococcus spp. e turbidez em todas as estações monitoradas.
A Tabela 7 apresenta as correlações obtidas entre

morrem mais rapidamente do que os protozoários (KEELEY \& FAUKNER, 2008).

O Comitê Distrital Provinciano Federal Canadense (2002), sobre água potável, afirma que a E. coli não é um bom indicador para C. parvum e G. lamblia. Para TALLON et al., (2005), mais trabalhos precisam ser feitos para correlacionar a presença de E. coli com a presença de patógenos, a fim de avaliar a necessidade da utilização de indicadores adicionais.

É importante descoccus spp. (NMP/100 mL), no período de dezembro de 2007 a novembro de 2008, Vargem das Flores - MG.

\begin{tabular}{|c|c|c|c|c|c|c|}
\hline E & $\begin{array}{c}\text { Cryptosporidium e } \\
\text { E. coli }\end{array}$ & $\begin{array}{c}\text { Cryptosporidium e } \\
\text { Enterococcus spp. }\end{array}$ & $\begin{array}{c}\text { Cryptosporidium e } \\
\text { turbidez }\end{array}$ & $\begin{array}{c}\text { Giardia e } \\
\text { E. coli }\end{array}$ & $\begin{array}{c}\text { Giardia e } \\
\text { Enterococcus spp. }\end{array}$ & $\begin{array}{c}\text { Giardia e } \\
\text { turbidez }\end{array}$ \\
\hline 1 & 0,315 & 0,703 & 0,140 & 0,472 & 0,780 & 0,426 \\
\hline 2 & $-0,093$ & 0,379 & $-0,149$ & 0,214 & 0,272 & $-0,128$ \\
\hline 3 & 0,305 & 0,397 & 0,480 & 0,258 & $-0,005$ & $-0,172$ \\
\hline 4 & 0,100 & 0,275 & $-0,059$ & $-0,028$ & $-0,173$ & $-0,079$ \\
\hline
\end{tabular}

E - Estação de coleta.

Os resultados em todas as estações apresentaram fracas correlações relativa aos protozoários Cryptosporidium spp. e Giardia spp. com o parâmetro físico turbidez.

Resultado similar foi verificado por Nieminski et al. (2008), que encontraram correlações pobres entre esses dois parâmetros após reunir dados de sete anos do monitoramento de sete estações de tratamento de água. Ao final do estudo os autores concluíram que a turbidez não era um indicador confiável para a presença de Cryptosporidium em águas.

A correlação obtida entre as variáveis Cryptosporidium spp. e E. coli também foi muito fraca em todas as estações monitoradas - Tabela 7. Portanto, a E. coli não se comportou como um indicador adequado da presença deste protozoário na presente pesquisa. Em relação à correlação entre Giardia spp. e E. coli, houve correlação moderada apenas na estação 1 .

Quanto ao Enterococcus spp. houve correlação alta com o Cryptosporidium spp. e com a Giardia spp. na estação 1 , contudo nas demais estações a correlação dessa bactéria com os protozoários mostrou-se fraca.

Em relação às estações 2, 3 e 4, as bactérias e os protozoários apresentaram correlação fraca. Embora Cryptosporidium, Giardia, E. coli e coliformes totais tenham origem nas fezes humanas e animais e são supostamente equanimente diluídos quando afluem ao corpo d'água, a falta de correlação significativa entre patógenos entéricos e indicadores fecais pode refletir diferentes taxas de sobrevivência e sedimentação. Enquanto a infecciosidade dos (oo)cistos é influenciada por vários fatores ambientais, inclusive temperatura, umidade, predação e exposição à radiação ultravioleta, eles são conhecidos por sua capacidade de sobreviver meses na água, diferentemente das bactérias de indicação fecal, que
3.4 Categorização das estações de monitoramento de acordo com as recomendações da Agência de Proteção Ambiental dos Estados Unidos (EPA)

Para concluir e sintetizar a ocorrência dos protozoários Giardia spp. e Cryptosporidium spp. na represa de Vargem das Flores, a Tabela 8 apresenta a estatística descritiva das concentrações de (oo)cistos verificadas em todas as estações monitoradas. Nessa tabela todos os valores das concentrações de (oo)cistos verificados foram corrigidos para $1 \mathrm{~L}$, pois a tabela da EPA "bin" é baseada em litro. Além disso, os resultados também foram corrigidos pelo percentual de recuperação do método, isto é $40 \%$ para oocistos e $30 \%$ para cistos (mesmo os dados de cistos não sendo abordados para tal discussão), pois com eles uma estação pode mudar de "bin" e de risco.

A partir das médias aritméticas das concentrações de (oo)cistos de Cryptosporidium spp. encontradas na
Tabela 8: Estatística descritiva dos parâmetros Cryptosporidium (oocisto/L) e Giardia (cisto/ L) - estações 1,2,3 e 4 multiplicado pelo percentual de recuperação.

\begin{tabular}{|l|c|c|c|c|c|c|c|c|}
\hline & \multicolumn{2}{|c|}{ Estacão 1 } & \multicolumn{2}{c|}{ Estação 2 } & \multicolumn{2}{c|}{ Estação 3 } & \multicolumn{2}{c|}{ Estação 4 } \\
\cline { 2 - 10 } & Oocisto & Cisto & Oocisto & Cisto & Oocisto & Cisto & Oocisto & Cisto \\
\hline Máximo & 0,2 & 0,4 & 0,4 & 0,4 & 0,4 & 0,8 & 0,4 & 0,3 \\
\hline Mínimo & 0 & 0 & 0 & 0 & 0 & 0 & 0 & 0 \\
\hline Média aritmética & 0,06 & 0,09 & 0,08 & 0,08 & 0,03 & 0,23 & 0,09 & 0,09 \\
\hline Mediana & 0,1 & 0,05 & 0,0 & 0,1 & 0,0 & 0,1 & 0,0 & 0,1 \\
\hline Desvio padrão & 0,1 & 0,1 & 0,1 & 0,1 & 0,1 & 0,3 & 0,2 & 0,1 \\
\hline$(\%)$ recuperação & 0,024 & 0,027 & 0,032 & 0,024 & 0,012 & 0,069 & 0,036 & 0,027 \\
\hline
\end{tabular}

(\%) valores multiplicados pelo percentual de recuperação, $40 \%$ e $30 \%$ para oocistos e cistos, respectivamente.

represa de Vargem das Flores (Tabela 8) foi possível enquadrar as estações monitoradas em uma categoria de acordo com a LT2 ESWTR (EPA 2006). A categorização está apresentada na Tabela 9. 
Tabela 9: Categorização segundo a LT2ESWTR - EPA 2006 - das estações de coleta (1, 2, 3 e 4) da represa de Vargem das Flores - M G.

\begin{tabular}{|l|c|c|c|c|c|c|c|c|}
\hline \multirow{2}{*}{ Mês } & \multicolumn{3}{|c|}{ Oocistos de Cryptosporidium/ L } & \multicolumn{4}{c|}{ Cistos de Giardia/ L } \\
\cline { 2 - 9 } & A. S. & R. B. & M. R. & B. V. & A. S. & R. B. & M. R. & B. V. \\
\hline Set/07 & 30 & N.C. & N.C. & N.C. & 3,0 & N.C. & N.C. & N.C. \\
\hline Mai/08 & 22 & 15,8 & 1,4 & 0,1 & 2,3 & 1,3 & 0,2 & N.D. \\
\hline Set/08 & 0,2 & 0,1 & 3,6 & 21,2 & 82,1 & 0,1 & N.D. & 1,4 \\
\hline Média & \multicolumn{4}{|c|}{10,4 oocistos/L } & \multicolumn{4}{c|}{14,9 cistos/L } \\
\hline
\end{tabular}

CC = Ciclo Completo; FD = Filtração Direta; * não requer tratamento adicional. quinzenal é feita a média das doze maiores concentrações para tal categorização. Por conseguinte, o enquadramento acima apenas complementa a discussão, mas não deve ser dado como verdade absoluta da categorização da represa de Vargem das Flores, uma vez que esse

Como a tecnologia de tratamento utilizada na ETA de Vargem das Flores é a filtração direta, a mesma é capaz de atender ao log de remoção requerido pela EPA, para as estações 1 - onde é realizada a captação - e estações 2,3 e 4 .

É importante ressaltar que a categorização apresentada na Tabela 9, foi feita a partir da média aritmética (multiplicada pelo percentual de recuperação do método) das concentrações de oocistos de Cryptosporidium spp. obtidas durante 12 meses e com análise de apenas 12 amostras, o que é relativamente pouco para caracterizar um ambiente aquático. Além disso, a EPA (2006) recomenda a análise em um período de 24 meses com coletas mensais ou quinzenais. Se for mensal é feita uma média aritmética das 24 amostras, se for manancial vem sofrendo cada dia mais ocupação urbana o que juntamente com a presença de animais, justifica a ocorrência ubíqua dos protozoários Cryptosporidium spp. e da Giardia spp. verifica da na represa.

Contudo, é importante mencionar um fato positivo que é a interceptação de esgotos na bacia hidrográfica que vem sendo feito pela Companhia de Saneamento, tal ação contribui para reduzir a concentração de cistos e oocistos na represa.

Para facilitar a compreensão, a Figura 5 dispõe um esquema da represa de Vargem das Flores e as médias das concentrações de oocistos de Cryptosporidium spp. e cistos de Giardia spp. em cada local de amostragem.

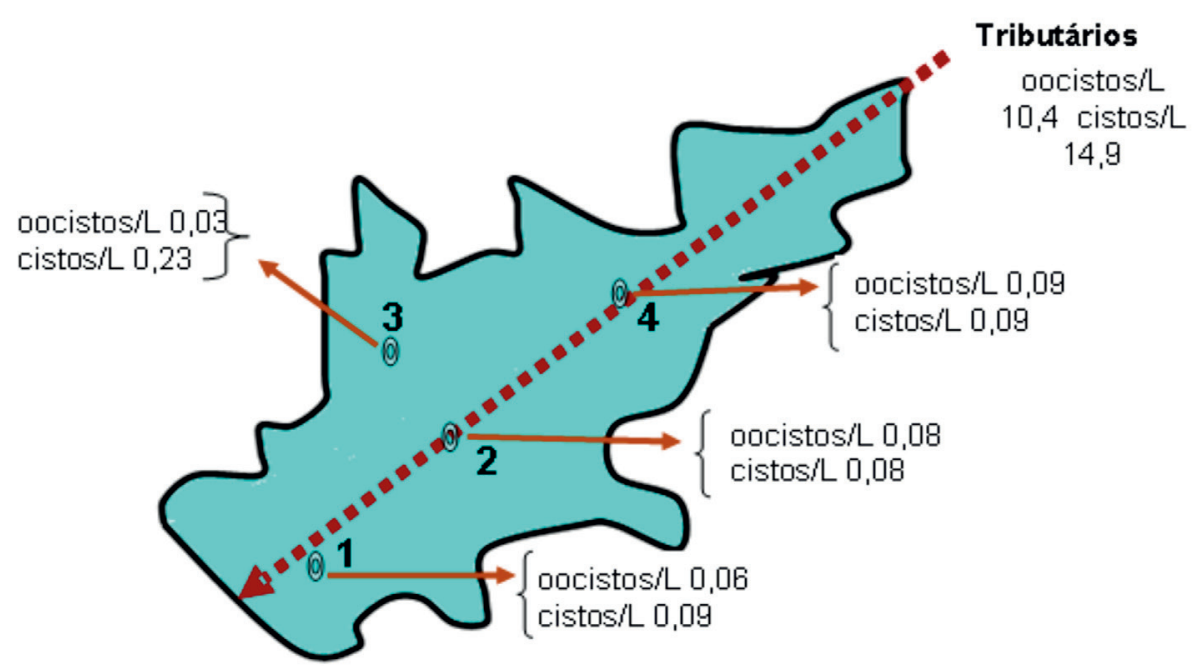

Figura 5: Esquema da distribuição dos (oo)cistos na represa de Vargem das Flores. Os valores ao lado de cada seta são relativos às concentrações médias de oocistos de Cryptosporidium spp. e cistos de Giardia spp.

A Tabela 10 apresenta as concentrações de (oo)cistos verificadas nos córregos tributários de Vargem das Flores, e a tabela 11 reúne os valores em log de redução das concentrações de (oo)cistos entre as estações e os córregos tributários.

Tabela 10: Concentração de (oo)cistos de Cryptosporidium spp. e de Giardia spp. nos córregos tributários da represa de Vargem das Flores, referentes as análises realizadas em setembro de 2007, maio e setembro de 2008.

\begin{tabular}{|c|l|c|l|c|}
\hline Estação & $\begin{array}{l}\text { Concentração média de } \\
\text { oocistos/L }\end{array}$ & Categoria & $\begin{array}{l}\text { Log de remoção - CC e } \\
\text { FD }\end{array}$ & Tratamento adicional \\
\hline $\begin{array}{c}1,2,3 \\
\text { e } 4\end{array}$ & $<0,075$ oocistos/L & 1 & $\begin{array}{l}\text { Filtração direta confere } \\
3 \log \text { - Satisfatório }\end{array}$ & $*$ \\
\hline & $>0,075$ até $<1,0$ oocisto/L & 2 & $\begin{array}{l}\text { Filtração direta confere } \\
3 \log \end{array}$ & $\begin{array}{l}\text { Necessário + 1 log adicional para } \\
\text { sistemas com ciclo completo, } \\
\text { filtração lenta ou filtração direta }\end{array}$ \\
\hline
\end{tabular}

A.S.: Água Suja; R.B.Ribeirão Betim; M.R.: Morro Redondo; B.V.: Bela Vista; N.C.: Não Coletado; N.D.: Não Detectado (para fins de cálculo da média foiconsiderado valor zero). 
Tabela 11: Log de redução das concentrações de (oo)cistos/L de Cryptosporidium spp. e de Giardia spp. obtidas nas estações 1, 2, 3, e 4 e nos córregos da represa de Vargem das Flores, MG no período de dezembro de 2007 a novembro de 2008.

\begin{tabular}{|l|c|c|c|c|c|c|c|c|}
\hline \multirow{2}{*}{ Local } & \multicolumn{7}{|c|}{ Log de redução } \\
\cline { 2 - 10 } & \multicolumn{9}{|c|}{\begin{tabular}{c} 
Oocistos/L \\
\cline { 2 - 9 }
\end{tabular}} & $\begin{array}{c}\text { Valor } \\
\text { inicial }\end{array}$ & $\begin{array}{c}\text { Valor } \\
\text { final }\end{array}$ & Efi. & $\begin{array}{c}\text { Log } \\
\text { redução }\end{array}$ & $\begin{array}{c}\text { Valor } \\
\text { inicial }\end{array}$ & $\begin{array}{c}\text { Valor } \\
\text { final }\end{array}$ & Efi. & $\begin{array}{c}\text { Log } \\
\text { redução }\end{array}$ \\
\hline $\begin{array}{l}\text { Média dos } \\
\text { córregos e E 4 }\end{array}$ & 10,4 & 0,09 & 0,99 & 2,0 & 14,9 & 0,09 & 0,99 & 2,2 \\
\hline Média E 4 e E 2 & 0,09 & 0,08 & 0,11 & 0,05 & 0,09 & 0,08 & 0,11 & 0,05 \\
\hline Média E 3 e E 2 & 0,03 & 0,08 & $\mathbf{- 1 , 6 7}$ & $\mathbf{- 0 , 4}$ & 0,23 & 0,08 & 0,65 & 0,4 \\
\hline Média E 2 e E 1 & 0,08 & 0,06 & 0,25 & 0,1 & 0,08 & 0,09 & $\mathbf{- 0 , 1 3}$ & $\mathbf{- 0 , 0 5}$ \\
\hline $\begin{array}{l}\text { Total (média dos } \\
\text { córregos e E 1) }\end{array}$ & 10,4 & 0,06 & 0,99 & 2,2 & 14,9 & 0,09 & 0,99 & 2,2 \\
\hline
\end{tabular}

Efi.: Eficiência = $($ Valor inicial - Valor final)/Valor inicial; Log redução $=-\log 10$ (1 - Efi); Valores em negrito = valor negativo; $\mathbf{E}$ = Estação; A média das concentrações de (oo)cistos dos córregos se trata da soma das médias das concentrações de (oo)cistos dos tributários - Água Suja, ribeirão Betim, Bela Vista e Morro Redondo, resultados não apresentados.

Conforme já dito, não houve diferença estatisticamente significativa relativa às concentrações de (oo)cistos entre as estações. Todavia, parece ter havido redução expressiva quando são comparadas as concentrações médias de (oo)cistos nos córregos tributários (Tabela 10) até a estação 1 (Tabela 11), com $\log$ de redução igual a 2,2. Desse ponto de vista, a represa de Vargem das Flores parece ter se comportado como uma barreira sanitária. Possivelmente um dos fatores que contribuiu para a redução na concentração dos protozoários ao longo da represa foi o tempo de residência da água, que é de três meses em períodos de chuva e 11 meses na seca. Entretanto, o número de amostras coletadas nos córregos não gerou dados suficientes para aplicação de um teste estatístico, o que não permite extrair maiores conclusões.

Ademais, ao que tudo indica, houve poluição entre as estações monitoradas, possivelmente advinda das cargas difusas de esgotos e dejetos na represa, isso explica a maior concentração média de oocistos de Cryptosporidium spp. na estação 2 em relação a estação 3, que está mais a montante. O mesmo ocorreu com a concentração média de cistos de Giardia spp. entre as estações 2 e 1.

Entretanto, é importante ressaltar que mesmo que as diferenças das concentrações de (oo)cistos de protozoários ao longo das estações (4, 3, 2 e 1) não tenham sido relevantes, em termos de Cryptosporidium e Giardia, aparentemente há um perigo maior nas estações localizadas à montante do que naquelas à jusante. $\mathrm{O}$ mesmo pode ocorrer em outros reservatórios lênticos, utilizados para abastecimento público. Logo, pode-se esperar que captar a água o mais distante possível da montante é um fator de segurança microbiológica, principalmente se esta sofre elevado aporte de efluentes, como é o caso da represa de Vargem das Flores.

\section{CONCLUSÕES}

Com base nos resultados da pesquisa, pode-se concluir que: e de Giardia spp. na represa de Vargem das Flores mostrou-se equânime e não indicou uma estação que apresente melhor qualidade de água tendo em vista esse parâmetro.

- $\quad$ As menores médias de oocistos de Cryptosporidium spp. foram encontradas na estação 3, embora a diferença não tenha sido estatisticamente significativa quando comparada com as estações 1,2 e 4 .

- Houve diluição expressiva da carga de (oo)cistos de Cryptosporidium spp. e de Giardia spp. dos córregos para a represa, indicando que a represa atuou como barreira sanitária.

- $\quad$ Os parâmetros E. coli, Enterococcus spp. e turbidez apresentaram correlação muito fraca com a presença dos (oo) cistos de Cryptosporidium spp. e de Giardia spp. e, portanto, de acordo com essa pesquisa, se mostraram pobres como indicadores da ocorrência desses protozoários na fonte.

- $\quad$ As estações 1, 2, 3 e 4 se enquadraram na categoria 1 da LT2ESWTR sendo suficiente o tratamento por filtração direta.

\section{AGRADECIMENTOS}

À Companhia de Saneamento de Minas Gerais (COPASA) pelo apoio logístico e instrumental para a realização dos ensaios, ao Programa de Pesquisa em Saneamento Básico - Prosab Edital 2006/Tema 1 - pelos recursos financeiros para a realização da pesquisa, ao $\mathrm{CNPq}$ pela bolsa concedida à primeira autora e à CAPES pela concessão da bolsa de estágio pós-doutoral ao quarto autor (Proc. 0925/09-8).

\section{REFERÊNCIAS}

ASTM. Active Standard. Standard Test Method for Enterococci in Water Using Enterolert. Developed by Subcommittee. D19.24, 2005. Disponível em: http://www.astm.org/database.cart/redline_pages/D6503.htm Acesso em: 10 dez. 2007.

APHA - AWWA - WEF (2005). Standard Methods for the examination of water and wastewater. 21th edition. American Public Health Association. 
American Water Works Association and Water Environment Federation.

BRASIL. Portaria do Ministério da Saúde. Resolução n. 518 de 25 de março de 2004. Brasília Diário Oficial da União, edição de 25 de março de 2004.

BROOKES, D. J.; ANTENUCCI, J.; HIPSEY, M.; BURCH, D. M.; ASHBOLT, J. N.; FERGUSON,C. 2004. Fate and transport of pathogens in lakes and reservoirs. Environment International, Vol. 30, 741-759 p.

CORNWELL, D. A.; BROW, R. A.; MACPHEE, M. J.; WICHSER, R. Applying the LT2ESWTR microbial toolbox. Journal American Water Works Association, p 76- 79, 2003.

FAYER, R, TROUT, J. M.; WALSH, E.; COLE, R. 2000. Rotifers ingest oocysts of Cryptosporidium parvum. Eukaryot Microbiol, Vol. 47, No. 2, 161-3 p. apud BROOKES, D. J.; ANTENUCCI, J.; HIPSEY, M.; BURCH, D. M.; ASHBOLT, J. N.; FERGUSON,C. 2004. Fate and transport of pathogens in lakes and reservoirs. Environment International, Vol. 30, 741$759 \mathrm{p}$.

FRANCO, B. M. R.; EBERHARDT, R. R.; CANTUSIO NETO, R. 2001. Occurrence of Cryptosporidium oocysts and Giardia cysts in raw water from the Atibaia river, Campinas, Brazil. Institute of Medicine Tropical, Vol. 43, No. 2, 109-11, p .

GOMES, L. N. L. Estudo da associação entre parâmetros bióticos a abióticos e a ocorrência de florações de cianobactérias no reservatório de Vargem das Flores - MG. 2008. 184f. Tese (Doutorado em Saneamento, Meio Ambiente e Recursos Hídricos) Escola de Engenharia da Universidade Federal de Minas Gerais, Belo Horizonte, 2008.

GOOGLE EARTH. Apresenta imagens de satélites, mapas, terrenos e edifícios em 3D. Disponível em: http://www.earth.google.com Acesso em: 5 jan. 2008.

HACHICH, E. M.; SATO, M. I. Z.; GALVANI, A. T.; MENEGON, N.; MUCCI, J. L. N. Giardia and Cryptosporidium in source waters of Sao Paulo State, Brazil. 2004. Water. Science and Technology, Vol. 50, 239-245 p.

HASHIMOTO, A.; HIRATA, T.; KUNIKANE, S. Occurrence of Cryptosporidium oocysts and Giardia cysts in a conventional water purification plant. 2001. Water Science and Technology, Vol. 43, No.12, 89-92 p.

HELLER, L.; BASTOS, R. K. X.; VIEIRA, M. B. C. M.; BEVILACQUA, P. D.; BRITO, L. L. A.; MOTA, S. M. M.; OLIVEIRA, A. A.; MACHADO, P. M.; SALVADOR, D. P; CARDOSO, A. B. 2004. Oocistos de Cryptosporidium e cistos de Giardia: circulação no ambiente risco à saúde humana. Epidemiologia e Serviços de Saúde, Vol. 13, No. 2, 79-92 p.

KARANIS, P.; KOURENTI, C.; SMITH, H. 2007. Waterborne transmission of protozoan parasites: A worldwide review of outbreaks and lessons learnt. Journal of Water and Health IWA, Vol. 5, No. 1, 1-38 p.

KEELEY, A.; FAUKNER, R. B. 2008. Influence of land use and watershed characteristics on protozoa contamination in a potential drinking water resources reservoir. Water Research, Science Direct - IWA, Vol. 42, 28032813 p.
LEAL, P. M. R. M. Avaliação do risco microbiológico associado à ocorrência de protozoários em sistemas de abastecimento de água: Um estudo na cidade de Divinópolis, Minas Gerais. 2005. 73f. Dissertação (Mestrado em Saneamento, Meio Ambiente e Recursos Hídricos) Escola de Engenharia da Universidade Federal de Minas Gerais, Belo Horizonte, 2005.

MACHADO, P. M. R.; CERQUEIRA, D. A. (2003). Ocorrência de (oo) cistos de Cryptosporidium e Giardia na área de captação e sua remoção no sistema de tratamento de água do rio das Velhas COPASA - Nova Lima MG. In: 22 Congresso Brasileiro de Engenharia Sanitária e Ambiental. 14 a 19 de setembro de 2003. Joinville-SC. CD rom.

NIEMINSKI, E.; DURRANT, G.; HOYT, M.; KIDD, R.; OWENS, M.; PETERSON, L.; PETERSON, S.; TANNER, W.; ROSEN, J.; CLANCY, J. (2008) Is monitoring for E. coli a good surrogate for Cryptosporidium ocurrence in water? AmericanWater Works Association- wqtc Conference Proceedings, 2008. CD rom.

SOUZA, A. D. Variações espaciais e temporais de parâmetros de qualidade de água em um reservatório tropical (represa de Vargem das Flores Contagem - MG) e suas implicações com aspectos limnológicos. 2003. 245f. Tese (Doutorado em Saneamento, Meio Ambiente e Recursos Hídricos) Escola de Engenharia da Universidade Federal de Minas Gerais, Belo Horizonte, 2003.

TALLON, P.; MAGAJNA, B.; LOFRANCO, C.; LEUNG, K. Microbial indicators of faecal contamination in water: a current perspective. 2005. Water, Air, and Soil Pollution, Vol. 166, 1139-166 p.

EPA. Method 1623: Cryptosporidium and Giardia in Water by filtration/ IMS/FA. United States Environmental Protection Agency, 2005.

EPA. Enhanced Surface Water Treatment Rule, Long Term 2. United States Environmental Protection Agency, 2006.

WORLD HEALTH ORGANIZATION (WHO). Water Treatment and Pathogen Control: Process Efficiency in Achieving Safe Drinking Water. Ed: LECHEVALLIER M. W.; AU K. K. ISBN: 184339069 8. IWA. 2004.

WORLD HEALTH ORGANIZATION (WHO). Guidelines for Drinking Water Quality. Cryptosporidium. EHC Cryptosporidium draft 2. 02 January, 2006. 